\title{
Ritidoplastia cervical reversa
}

\section{Reverse cervical rhytidectomy}

\section{Aristoteles Bersou Junior ${ }^{1}$}

Guilherme Bersou²

Trabalho realizado no Hospital Saint Paul, São Paulo, SP, Brasil.

Artigo submetido pelo SGP (Sistema de Gestão de Publicações) da RBCP.

Artigo recebido: 6/7/2010 Artigo aceito: 18/8/2010

\section{RESUMO}

Rejuvenescimento da região cervical anterior por técnica usualmente utilizada nas ritidoplastias é indicado para casos de pacientes com problemas de flacidez, associada ou não com bandas de platisma, com ou sem adiposidade localizada ou mesmo generalizada. Nos casos em que estes aspectos estão localizados no terço cervical inferior e, em particular, junto à fúrcula esternal e clavículas, observamos a possibilidade de realizar a ritidoplastia cervical reversa.

Descritores: Ritidoplastia. Cirurgia plástica/métodos. Rejuvenescimento.

\section{SUMMARY}

Neck rejuvenation by technique usually used in rhytidectomy is recommended for cases of patients suffering from sagging either or not associated with platisma bands with or without generalized adiposity. In cases which these areas are located in the lower cervical, and particularly near the sternal notch and clavicles, we observed the possibility of reverse cervical rhytedectomy.

Descriptors: Rhytidoplasty. Plastic surgery/methods. Rejuvenation.

\section{INTRODUÇÃO}

A pele do pescoço e o músculo platisma efetivamente recobrem uma das regiões do corpo que mais recebe estímulos impostos para os movimentos da cabeça. Ao longo das décadas, os efeitos do tempo e do uso determinam flacidez e o aparecimento de bandas músculo-cutâneas, com extensão e formatos variados, associadas ou não a depósitos adiposos localizados abaixo do mento ou mesmo generalizados em toda a extensão do pescoço.

Nas décadas mais avançadas, o descenso do conjunto pele, celular subcutâneo em volumes variados e do platisma chega a formar uma dobra por sobre a fúrcula esternal e clavículas. Esta diversificação determina efeitos pouco estéticos, queixa frequente de pacientes de ambos os sexos, que buscam na cirurgia a resolução do problema.
A ritidoplastia cervical tem sido descrita como um procedimento cirúrgico destinado a porporcionar efeitos estéticos de rejuvenescimento, mediante incisões submentoniana, pré e retro-auriculares, dissecação da pele em extensões variadas, combinada ou não com lipoaspiração, SMAS, platisma, realizadas ou não num único tempo operatório.

Os pacientes com maior flacidez e ptose cutânea, associada ou não a adiposidade no segmento cervical inferior junto à incisura jugular, fúrcula esternal e clavículas, exigem ampla dissecação cutânea através das incisões peri-auricularesm com riscos de comprometer a vitalidade destes retalhos, além da maior possibilidade de hematoma.

Para casos específicos como os descritos, sem e mesmo com cicatriz cervical pós-tireoidectomia pela via de acesso tipo Kocher ${ }^{1}$, o presente artigo registra um procedimento chamado ritidoplastia cervical reversa. 


\section{MÉTODO}

\section{Técnica Cirúrgica}

A demarcação cutânea é realizada com a paciente em posição ortostática e previamente à pré-medicação anestésica. Compreende a forma de uma elipse, com cerca de 15 a $17 \mathrm{~cm}$ de comprimento por 2 a $3 \mathrm{~cm}$ de largura, posicionada entre a inserção do músculo esternocleidomastoídeo, no nível das clavículas, e a incisura jugular, bilateralmente. A seguir, 3 a 4 linhas verticais demarcam a pele, perpendiculares ao maior eixo da elipse, orientando a sutura das bordas das incisões.

Finalmente, uma segunda linha elipsóide, com $4 \mathrm{~cm}$ acima e $1 \mathrm{~cm}$ abaixo das bordas superior e inferior da primeira elipse, delimita a área cirúrgica e a dissecção da pele. Nos casos de cicatriz prévia de tireoidectomia, a mesma fica incluída na área do fuso a ser ressecado (Figura 1A).

A cirurgia é realizada com a paciente sob sedação e anestesia local, mediante uma solução de $20 \mathrm{ml}$ de xilocaína a $2 \%$ sem adrenalina, diluída em $250 \mathrm{ml}$ de ringer lactado e $1 \mathrm{ml}$ de adrenalina. A infiltração cutânea é do tipo expansiva (Figura 1B).

São realizadas incisão e ressecção da cicatriz tireoidiana quando existente e dissecção da pele e do subcutâneo até o músculo platisma, com bisturi lâmina 15 , no limite inferior da elipse e cranial, até atingir a proeminência laríngea, distante até cerca de $8 \mathrm{~cm}$ da fúrcula esternal. Nos limites laterais, a dissecção é ampla e em torno dos ângulos da elipse. Procede-se, então, à hemostasia rigorosa.

Na ausência de cicatriz tireoidiana, a incisão cutânea é realizada paralelamente à linha inferior da elipse e acima cerca de 3 a $4 \mathrm{~mm}$. Tomando-se como base as demarcações verticais, a pele dissecada é tracionada caudalmente. Realizada incisão cutânea vertical na linha média do retalho até o limite superior a ser ressecado. Um ponto de reparo une a borda da incisão inferior com este limite incisado. O mesmo é realizado com as demarcações verticais laterais com pontos, que são incisadas e fixadas. Realizada ressecção do excesso de pele e eliminação dos pontos provisórios. Pontos de Baroudi ${ }^{2}$ são aplicados na área dissecada com fio absorvível de monocryl 5.0.

A sutura final é realizada com fio absorvível, com pontos separados no plano dérmico, e contínua, no plano intracuticular. Realizado curativo com fita adesiva porosa, com $2 \mathrm{~cm}$ de largura, recortada com pequenos quadrados em toda a sua extensão. As Figuras 1C a 1J ilustram detalhes transoperatórios e as Figuras $1 \mathrm{~K}$ a $1 \mathrm{~N}$ demonstram os aspectos do pré e do $5^{\circ}$ mês de pós-operatório.

As Figuras 2A a 2D e as Figuras $3 \mathrm{~A}$ a $3 \mathrm{~F}$ complementam a ilustração da qualidade dos resultados a longo prazo.

\section{DISCUSSÃO}

A ritidoplastia cervical reversa tem indicação específica para problemas de acentuada flacidez de pele posicionada no segmento cervical inferior junto à incisura jugular, fúrcula esternal e clavicular, em particular ainda nos pacientes portadores de cicatriz tireoidiana.

Nosso primeiro paciente, operado em 2002, era do sexo masculino, apresentava um problema de excessos de pele e pregas cutâneas ao longo do segmento inferior da região cervical, que lhe perturbava esteticamente, em particular no uso de gravata. Não tinha cicatriz tireoidiana e nem aceitava a possibilidade de ritidoplastia convencional.

A cirurgia seguiu os preceitos técnicos descritos, sendo depois utilizada seletivamente para casos similares, com e sem cicatriz pós-tireoidectomia.

A demarcação de forma elíptica tem a sua posição determinada como foi descrita, após testes bidigitais na pele para avaliação dos excessos e de elasticidade, sempre combinados com movimentações criteriosas da cabeça para evitar ressecções além ou aquém da necessária. As linhas verticais de demarcação orientam os pontos de reparo na ressecção dos excessos cutâneos, para melhor ajuste na linha de sutura. Nos casos com cicatriz de tireoidectomia prévia, a mesma foi incluída na demarcação elíptica, sendo ressecada completamente no início da cirurgia.

A infiltração anestésica expansiva facilita a dissecção, a hemostasia e eventuais bridas cicatriciais da tireoidectomia, quando presentes. A dissecção cranial da pele é por estimativa, onde sucessivas trações no sentido caudal do retalho orientam quando parar e quanto ressecar sem tensões. Junto às extremidades, a dissecção é circular, para liberar os ângulos e evitar "dog-ear" no final da sutura. Após a ressecção dos excessos, a sutura final é procedida com pontos de adesão com fio absorvível, com o intuito de reduzir o espaço morto e fixar o retalho cutâneo ao plano do músculo platisma, reduzindo a possibilidade de tensão na sutura, o alargamento da cicatriz e a alteração na sua posição.

O único curativo é da aplicação de adesivo poroso de $2 \mathrm{~cm}$ de largura, o qual dobrado previamente sobre o lado contrário ao da cola, e recortado em pequenos triângulos. A seguir, o curativo é aplicado ao longo e sobre a linha de 

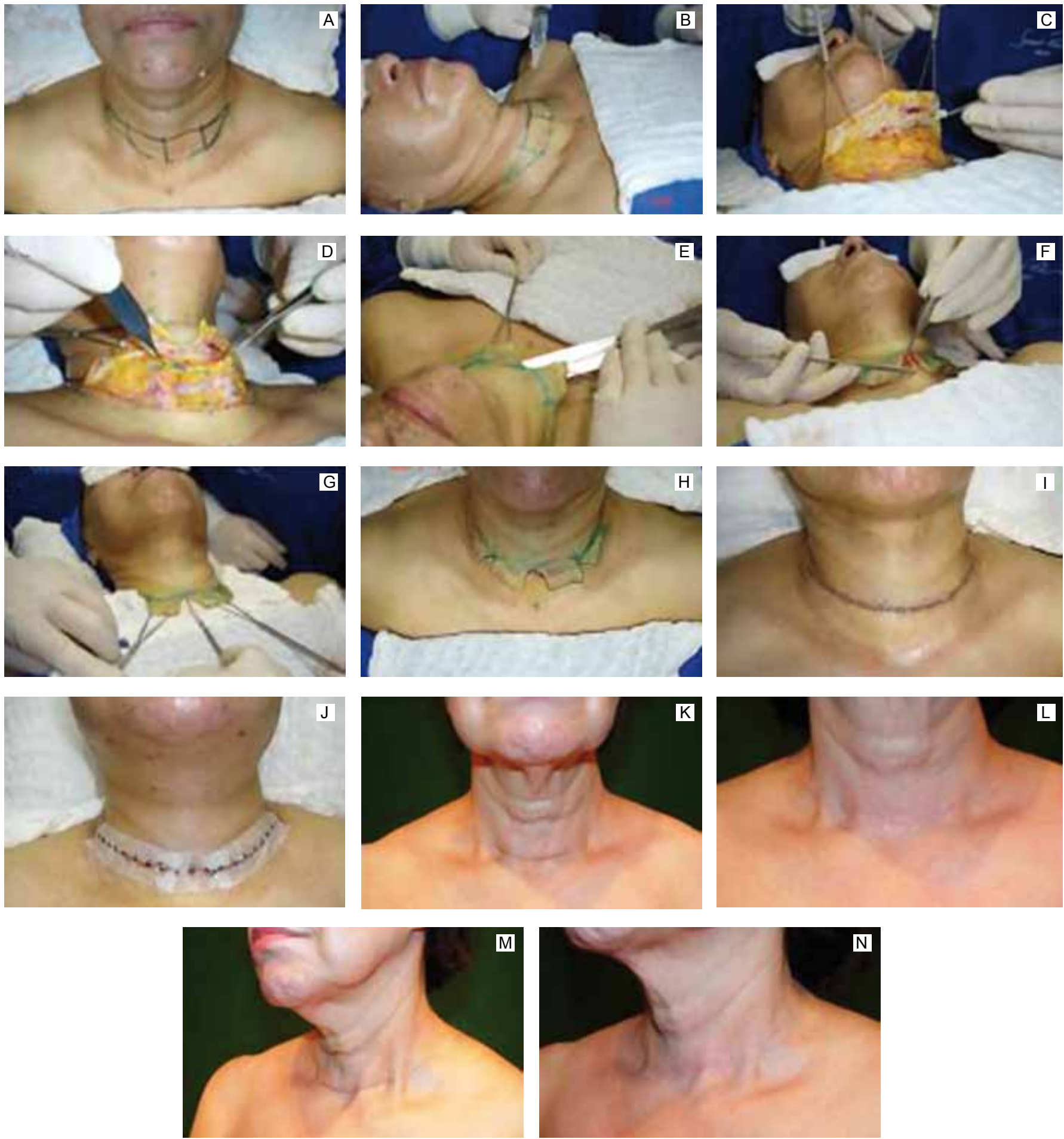

Figura 1 - A: Transoperatório de paciente de 57 anos de idade, submetida a ritidoplastia cervical reversa, após demarcação cutânea sob a forma de um fuso na região cervical inferior, que envolve cicatriz de tireoidectomia prévia. Três linhas vertical eqüidistantes, que cruzam a demarcação horizontal, orientam a sutura após ressecção dos excessos cutâneos. B: Infiltração anestésica local com vasoconstrictor. $\boldsymbol{C}$ e $\boldsymbol{D}$ : Incisão cutânea transfixante até o plano do músculo platisma. Dissecção cutânea-muscular até o nivel da proeminência laringeana. $\boldsymbol{E}$, $\boldsymbol{F}$ e $\boldsymbol{G}$ : Manobras de avaliação para ressecar o excesso cutâneo, com pontos de adesão no segmento cutâneo dissecado. $\boldsymbol{H}$ : Retalho cutâneo em excesso é incisado em três segmentos e suturas provisórias são aplicadas. I: Sutura final por planos após a ressecção dos excessos cutâneos. $\boldsymbol{J}$ : Curativo com fita adesiva porosa vazada sob a forma de quadrados, para permitir melhor drenagem. $\boldsymbol{K}, \boldsymbol{L}, \boldsymbol{M}$ e $\boldsymbol{N}$ : Vista anterior e lateral do pré e $5^{\circ}$ mês de pós-operatório, que mostra a qualidade da pele cervical e a posição da cicatriz residual. 

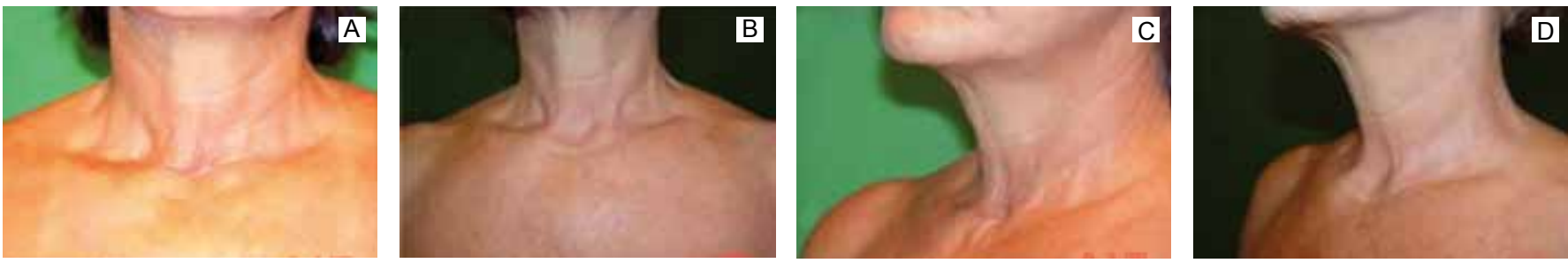

Figura 2 - A, B, C e D: Aspectos pré e pós-operatório de 4 anos, em paciente caucasiana, de 53 anos de idade na ocasião da cirurgia, vista anterior e lateral do pescoço, submetida ao procedimento descrito. Presença de uma linha cicatricial fina, hipocrômica, ao longo da confluência do pescoço com a clavícula e manúbrio esternal.
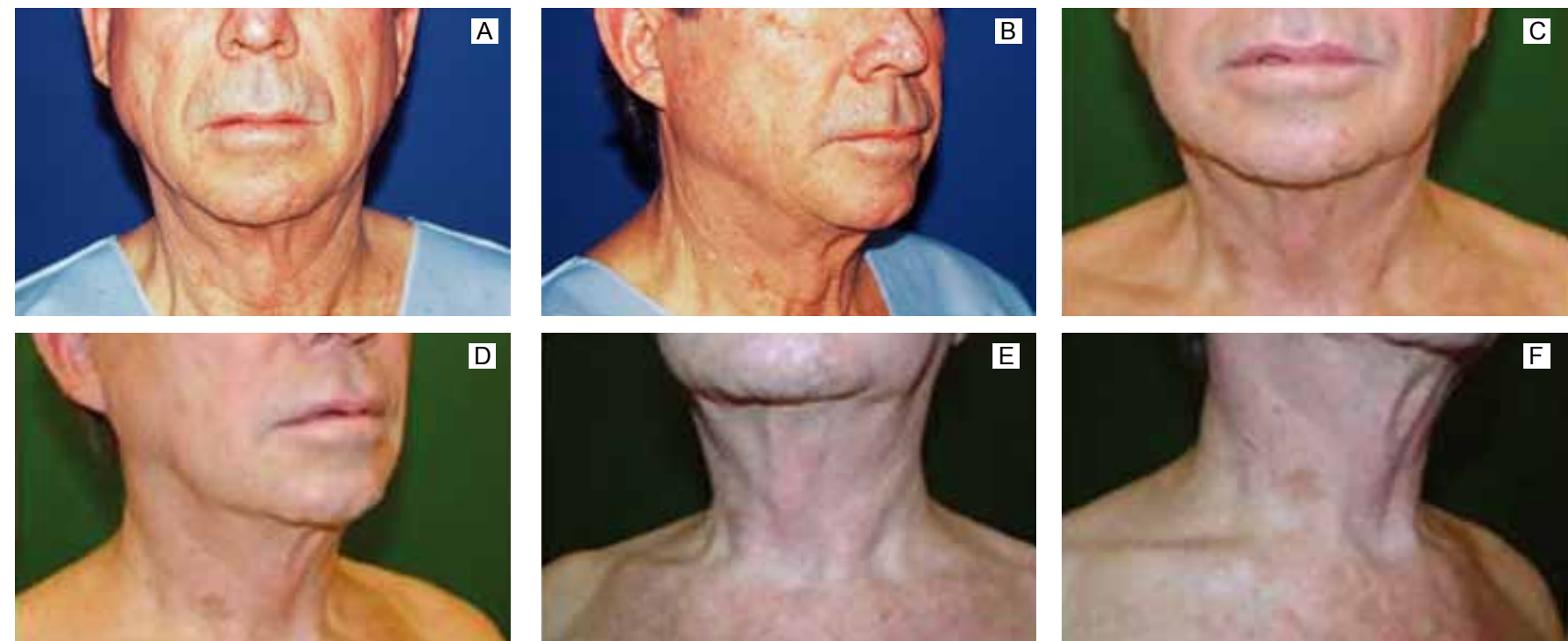

Figura 3 - A e B: Pré-operatório da vista anterior e lateral do pescoço de paciente do sexo masculino, de 69 anos de idade, submetido ao procedimento descrito. $\boldsymbol{C}$ e $\boldsymbol{D}$ : Mesmo paciente aos 3 anos de pós-operatório. $\boldsymbol{E}$ e $\boldsymbol{F}$ : Aspecto do paciente aos 7 anos de pós-operatório. Cicatriz e condições estéticas do pescoço demonstram a qualidade do resultado.

sutura, os espaços cortados tomam a forma de quadrados pequenos, que facilitam a permeabilização e visualização da sutura. Esta manobra condiciona a drenagem de exsudatos, a limpeza com água e sabão neutro e povidine aplicados diariamente. A fita é mantida por 15 dias, ou trocada por razões várias ou ainda antes, por causas alérgicas.

A tração crânio-caudal do retalho cutâneo dissecado, a ressecção dos excessos e o posicionamento da sutura têm deixado cicatrizes pouco aparentes quando sobre a incisura jugular, por ser uma área de menor mobilidade. A cicatriz da tireoidectomia, na sua maioria, é de ótima qualidade e posicionamento. Temos observado que o seu alongamento, quando coincidente com as linhas de força e as rugas da região, deve também seguir o mesmo aspecto.
A combinação da técnica proposta com a ritidoplastia convencional é factível, desde que se respeite a vascularização dos retalhos. Para concluir, a extensão da cicatriz varia com a qualidade do problema, porém sempre maior do que o comprimento prévio da tireoidectomia. A sua posição e extensão devem compensar a qualidade estética deixada na região cervical.

\section{CONCLUSÕES}

A ritidoplastia reversa cervical representa uma opção para casos específicos de pacientes com e mesmo sem cicatriz de tireoidectomia, com problema de flacidez localizada ao longo do terço inferior do pescoço. A cicatriz residual é 
linear e de extensão variada, horizontalmente posicionada junto à fúrcula esternal e clavículas. A relação custo-benefício tem permitido continuar empregando o procedimento, pela qualidade dos resultados e pela pequena extensão da cirurgia, registrando-se, entretanto, a seletividade da sua indicação.

\section{REFERÊNCIAS}

1. Carvalho MB. Tratado de tireóide e paratireóide. Rio de Janeiro:Ed. Rubio;2007. p.631.

2. Moore K. Anatomia orientada para clínica. $3^{\mathrm{a}}$ ed. Rio de Janeiro:Guanabara Koogan;1994. p.713.

3. Baroudi R, Ferreira CA. Seroma: how to avoid and how to treat it. Aesthet. Surg J. 1998;18(6):439-41.

\section{Correspondência para:}

Aristoteles Bersou Junior

Av. Cidade Jardim, 993 - Cidade Jardim - São Paulo,SP, Brasil - CEP 01453-000

E-mail: abersoujr@clinicabersou.com.br 